\title{
ASSESSMENT OF THE ROLE OF CRP AND PLATELET COUNT IN EARLY NEONATAL SEPSIS
}

Dr Sachin Walchand Shaha

Associate Professor, Department of Pediatrics, Vedanta Institute of Medical Sciences, Saswand, Palghar, Maharashtra

Article Info: Received 03 September 2021; Accepted 12 October 2021

DOI: https://doi.org/10.32553/ijmbs.v5i10.2237

Corresponding author: Dr Sachin Walchand Shaha

Conflict of interest: No conflict of interest.

\section{Abstract}

Material and Methods: A Prospective study was performed in the department of Pediatrics in territory care institute for the duration of 8 months. Forty newborns were included in the study group to satisfy including criteria. Before antibiotic treatment, neonates CRP and platelet count were assessed. Data were analyzed by SPSS software.

Results: Out of the 40 cases, 22 were male babies, and the rest 18 were female. Blood culture was positive in 19 out of the 40 cases, CRP was positive in 21 cases, and thrombocytopenia was observed in 16 cases. Klebsiella is the commonest gram organism causing sepsis in the Neonatal Intensive Care Unit. The Gram-positive organisms grown are Coagulase Positive and Coagulasenegative Staphylococci, Group B Beta Hemolytic Streptococcus, and Enterococcus. Out of 16 thrombocytopenia neonatal, 15 shows Gram-negative and 1 shows gram-positive blood culture.

Conclusion: Qualitative analysis of C-reactive protein can be used as an early marker of sepsis, especially in resource-limited settings. Although thrombocytopenia occurs predominantly in gramnegative sepsis, there is insufficient evidence to support the use of platelet count to differentiate between gram-positive and gram-negative sepsis.

Keywords: CRP, Platelet count,blood cultures, sepsis.

\section{Introduction}

Due to the advances in the intensive care of the neonatal patients it has lead to an decrease in mortality and morbidity of the patients. However, infectious episodes in the early postnatal period still remain serious and potentially life-threatening events with a mortality rate of up to $50 \%$ in very premature infants. ${ }^{1,2}$ In various developed countries the incident rate of sepsis in neonatal varies from 1 to 4 cases per 1000 birth. In the developing countries this rate increases to $11-30$ cases per 1000 births. $^{3-6}$ Today also sepsis remains the most common diseases in the period of neonatal. It is still considered as major casue of morbidity and mortality. ${ }^{7,8}$ As per the World health organization the mortality rate in the children at the age below 5 years is mostly due to infection and the perinatal causes. ${ }^{9-12}$
Because of high vulnerability of neonates to infections, it is mandatory to diagnose and treat neonatal sepsis at early stages. Blood culture is the gold standard for definite diagnosis but it takes at least 72 hours by which time the infection may have progressed. ${ }^{14,15}$ Due to nonspecific clinical features of sepsis and also because of non-availability of blood culture results within 48 hours, the early diagnosis of neonatal sepsis is still a major problem. ${ }^{16,17}$

The newborn infant is susceptible to infection due to immaturity of both natural and acquired immune systems. Sepsis is considered a strong possibility for any clinical deterioration in a neonatal state. It is either early-onset (7 days), and it is considered as one of the important leading factors for neonatal mortality and 
morbidity. ${ }^{18}$ Consequently, early diagnosis is very important as it helps in beginning antibiotic therapy early, thereby reducing neonatal mortality. ${ }^{19}$ Blood culture remains the gold standard in identifying the infecting organism and provides vital information regarding the antibiotic sensitivity pattern so that proper usage of drugs can be made. However, blood culture generally takes at least 48 to 72 hours to detect bacterial growth, which causes a considerable time lag in initiating appropriate treatment. In addition, it has its disadvantages in CRP is an acute-phase protein synthesized in the liver in response to infection or inflammation. CRP is a biomarker and is elevated in sepsis. ${ }^{20,21}$ Normal CRP concentration in healthy neonates is usually lower than $6 \mathrm{mg} / \mathrm{L}$. Values more than this are considered CRP Positive. To solve this challenging problem the physicians are always in need of advance method of early prediction and detection, diagnosis of the neonatal sepsis so that early therapy can be initiated and it can be helpful in reducing the mortality rate and also helps in improvement of over al health of children. This way we can reduce the hospital stay and can also be finical help to the family. The need of the hour is to identify a test to confirm the presence of sepsis earlier and find out a parameter that reliably distinguishes between gram-positive and gramnegative sepsis, which may help in choosing the appropriate antibiotic without having to rely on the empirical coverage.

Present study was done with an aim to evaluate the role of CRP and platelet count in early neonatal sepsis

\section{Material and Methods}

A Prospective study was performed in the department of Pediatrics in territory care institute for the duration of 8 months. Informed consent from the parents was obtained. Forty newborns were included in the study group to satisfy including criteria. Newborns belonging to both sexes were admitted to this study. Only newborns within seven days of life were included in the study population.

Inclusion criteria were: Temperature instability - hypothermia or fever, lethargy, poor cry, refusal of feeds, vomiting, ileus, abdominal distension, poor peripheral perfusion, neonatal convulsions, irritability, hypotonia, altered sensorium.

Before antibiotic treatment, neonates CRP and platelet count were assessed.

\section{Statistical analysis}

The recorded data was collected and entered in a spreadsheet computer program (Microsoft Excel 2007) \& exported to data of SPSS version 15 (SPSS Inc., Chicago, Illinois, USA). For all tests, confidence level and level of significance were set at $95 \%$ and $5 \%$ respectively.

\section{Results}

Forty newborns that fulfilled the inclusion criteria were included in the study. Out of the 40 cases, 22 were male babies, and the rest 18 were female. On categorizing the newborns based on birth weight, 4 babies were of low birth weight, 34 newborns were of normal birth weight, and 2 babies were overweight, as depicted. Blood culture was positive in 19 out of the 40 cases, CRP was positive in 21 cases, and thrombocytopenia was observed in 16 cases. CRP was found to be positive in more number of blood culture-positive cases than blood culture-negative cases, as depicted.

In our study, thrombocytopenia was observed in 16 cases, out of which 15 were of culturepositive sepsis and in 1 case of culturenegative sepsis. Apart from this, the normal platelet count was observed in 24 patients, out of whom 3 were culture-positive, and 21 were of the culture-negative group.

Klebsiella is the commonest gram organism causing sepsis in the Neonatal Intensive Care Unit. The other gramnegative organisms encountered are Escherichia Coli, 
Pseudomonas, Enterobacter, and Acinetobacter. The Gram-positive organisms grown are Coagulase Positive and Coagulasenegative Staphylococci, Group B Beta
Hemolytic Streptococcus, and Enterococcus. Out of 16 thrombocytopenia neonatal, 15 shows Gram-negative and 1 shows grampositive blood culture.

Table 1: Distribution of study participants according to Gender

\begin{tabular}{|l|l|l|}
\hline Gender & Number & Percentage \\
\hline Male & 22 & 55 \\
\hline Female & 18 & 45 \\
\hline Total & 40 & 100 \\
\hline
\end{tabular}

Table 2: Cross-tabulation of CRP and Culture test

\begin{tabular}{|l|l|l|l|}
\hline Variable & Positive & Negative & Total \\
\hline CRP & 21 & 19 & 40 \\
\hline Culture & 19 & 21 & 40 \\
\hline
\end{tabular}

\section{Discussion}

Neonatal Sepsis is one of the major causes of neonatal mortality in developing countries. contributing to $15 \%$ deaths. ${ }^{22}$ In Pakistan the neonatal mortality rate is $54 / 1000$ live births which is very high. ${ }^{23}$ The early signs and symptoms of sepsis in neonates are often nonspecific and make it difficult to establish an early clinical diagnosis. Blood culture is a reliable investigation with a yield of up to $75 \%$ but it is time consuming and demands a well equipped laboratory setting.

Out of the 40 babies under evaluation, 22 were male babies, and the rest 18 were female. Blood culture was positive in 19 out of the 40 cases, CRP was positive in 21 cases, and thrombocytopenia was observed in 16 cases. Our study's rate of culture positivity was $47.5 \%$, which correlates with Al-Musawi et al, whose study revealed a $45 \%$ growth in culture. This is also in accordance with the study by Shyamala et al., which showed a culturepositive rate of $51.3 \%$. ${ }^{24,25}$ Similarly, Sriram et al reported a $50.4 \%$ on culture positivity in a study group of 115 neonates. ${ }^{26}$ It correlates with the study of Shyamala et al. ${ }^{25}$ In a study by Sherazi et al the main organisms found on blood culture were acinetobacter (35\%), Klebsiella pneumoniae (25\%), Staphylococcus aureus (19\%), E-coli (12\%), Pseudomonas $(2 \%)$ and Proteus vulgaris in $4 \%$ of the patients which are comparable with blood culture results of our study. ${ }^{27}$

The diagnostic strength of $\mathrm{C}$ - reactive protein has been thoroughly studied in neonatal sepsis. $^{28}$ The overall prevalence of thrombocytopenia in our study group is $81.8 \%$, according to the study done by Torkaman et al. ${ }^{29}$ It also correlates with the study done by Shyamala et al, which showed a $69.9 \%$ prevalence of thrombocytopenia. ${ }^{25}$ Manzoni et al had reciprocated our analysis, concluding that thrombocytopenia is not an organismspecific marker of sepsis. ${ }^{30}$ On the other hand, the analysis by Scheifele et al is in contrast with our study and states that the endotoxinemia in necrotizing enterocolitis with gram-negative organisms leads to thrombocytopenia. ${ }^{31}$

Early diagnosis of neonatal sepsis is very difficult when it is based only on clinical signs. The clinical profile is neither uniform nor specific and could mislead the health care professionals. Keeping in mind the mortality caused by neonatal sepsis, empirical treatment should not be delayed but again this can result in unnecessary and prolonged exposure to antibiotics in this early age group. Cost 
effective and rapid diagnostic tool is one way to tackle this issue. CRP and leukocyte count should be considered to decrease neonatal mortality rate in the country.

\section{Conclusion}

Qualitative analysis of C-reactive protein can be used as an early marker of sepsis, especially in resource-limited settings. Although thrombocytopenia occurs predominantly in gram-negative sepsis, there is insufficient evidence to support the use of platelet count to differentiate between gram-positive and gramnegative sepsis.

\section{References}

1. Fanaroff AA, Stoll BJ, Wright LL, Carlo WA, Ehrenkranz RA, Stark AR, et al. Trends in neonatal morbidity and mortality for very low birthweight infants. American Journal of Obstetrics and Gynecology. 2007;196(2):147.e1-8-.e1-8.

2. Remington JS, Klein JO. Developmental immunology and role of host defenses in neonatal susceptibility. In: Remington JS, Klein, editors. Infectious Diseases of the Fetus and Newborn Infant. Philadelphia: Saunders; 1990. p. 17-67.

3. Stoll BJ. Infections of neonatal infant. In: Bahrman KE, Kliegman RM, Jenson HB, editors. Nelson Textbook of Paediatrics. Philadelphia: WB Saunders 2009; 623-40

4. Misra RN, Jadhav SV, Ghosh P. Role of sepsis screen in the diagnosis of neonatal sepsis. Medical Journal of Dr. D. Y Patil University 2013;6(3):254-57.

5. Jaswal RS, Kaushal RK, Geol A. Role of C-reactive protein in deciding the duration of the antibiotic therapy in neonatal septicemia. Indian Paediatrics 2003;40:800-83.

6. Sucilathangam G, Amuthavalli K, Velvizhi G. Early diagnostic marker for neonatal sepsis: Comparing procalcitonin and $\mathrm{C}$ reactive protein. JCDR 2012;627-31.

7. Stoll BJ, Hansen NI, Higgins RD. Low birth weight preterm infants with early onset neonatal sepsis: the predominance of gram-negative infections. Pediatr J Infect Dis 2005; 24: 635- 39.

8. Shim GH, Kim SD, Kim SH, Lee HJ. Trends in epidemiology of neonatal sepsis. J Koren Med Sci 2011;26:284-89.

9. WHO. World Health Report. Geneva: World Health Organization 2005.

10. Debnath J, Debnath T, Majumdar B. Role and significance of $\mathrm{C}$-reactive protein in neonatal sepsis. Journal of Biomedical and Pharmaceutical research 2013;2(2):51-55.

11. Largo MG and Stekelenburg J. The Millenium project of United Nations, focusing on adequate postpartum care to reduce maternal and neonatal mortality world-wide. Ned Tijdschr Genesskd 2006; 150: 1143-47.

12. Lawn JE, Cousens S, Zupan J. 4 million neonatal deaths: when ? where? Why? Lancet 2005;365:891-900.

13. Omene JA. Neonatal septicemia in Benin city, Nigeria: A Review of 74 cases. Trop Geogr Med 1979;31:35-39.

14. Buttery JP. Blood cultures in newborns and children: optimising an everyday test. Arch Dis Child Fetal Neonatal Ed 2002;87:2528.

15. West BA, Peterside O, Ugwu R. Prospective evaluation of usefulness of Creactive protein in the diagnosis of neonatal sepsis. Antimicrobial Resistance and Infection Control 2012;1:22-25.

16. Sluncheva B, Vakrilova L, Emilova K. Inborn bacterial infections during neonatal period. Akush Ginekol 2006; 45: 42-48.

17. Mathai E, Christopher U, Mathai M, Kumar A. Is C-reactive protein level useful in differentiating infected from uninfected neonates . Indian Pediatr 2004; 41: 895900.

18. Dhananjay BS, Sunil KN. Comparison of biochemical and pathological markers in neonates with sepsis and neonates without sepsis. Int J Biol Med Res. 2011;2(4):1131-4. 
19. Ranjan R, Jerupula S, Bhagwani DK. Procalcitonin and CRP markers in neonatal sepsis. International Journal of Scientific Research. 2019;8(2).

20. Chiesa C, Paner A, Osborn J. Diagnosis of neonatal sepsis: A clinical and laboratory challenge. Clinical Chemistry. 2004; 10:279-87.

21. Pacifico L, Panero A, Colarizi P, Matrunola M, Simonetti AF, Chiesa C. Neonatal Candida albicans septic thrombosis of the portal vein followed by cavernous transformation of the vessel. Journal of clinical microbiology. 2004;42(9):4379-82.

22. Chacko B, Sohi I. Early onset neonatal sepsis. Indian J Pediatr 2005; 72: 23-26.

23. National Institute of Population Studies (NIPS) [Pakistan] and Macro International Inc. Pakistan Demographic and Health Survey (DHS) 2006-07 Islamabad, Pakistan: National Institute of Population Studies and Macro International Inc; 2008.

24. Al-Musawi ZM. The role of CRP in the diagnosis and duration of antibiotic therapy in neonatal sepsis. Kufa Med J. 2008;11:33-40.

25. Shyamala KV, Subbalakshmi NK, Raghuveera K. Role of CRP and platelet count in newborn sepsis. J Chi Clin Med. 2010;5:474.

26. Sriram R. Correlation of blood culture results with the sepsis score and the sepsis screen in the diagnosis of neonatal septicemia. Int $\mathrm{J}$ Biol Med Res. 2011;2(1):360-8.

27. Shirazi H, Riaz S, Tahir R. Role of the hematological profile in early diagnosis of neonatal sepsis. Ann Pak Inst Med Sci 2010; 6: 152-56.

28. Manucha V, Rusia U, Sikka M, Faridi MM, Madan N. Utility of hematological parameters and C-reactive protein in the detection of neonatal sepsis. J Pediatr Clin Health 2002; 38: 459-64.

29. Torkaman M, Afsharpaiman S H, Hoseini M J, Moradi M. Platelet count and neonatal sepsis: a high prevalence of Enterobacter spp. Sing Med J. 2009;50:482-5.

30. Manzoni P, Mostert M, Galletto P, Gastaldo L, Gallo E, Agriesti G, Farina D. Is thrombocytopenia suggestive of organism-specific response in neonatal sepsis? Pediatr Int. 2009;51(2):206-10.

31. Scheifele DW, Olsen EM, Pendray MR. Endotoxinemia and thrombocytopenia during neonatal necrotizing enterocolitis. Am J Clin Pathol. 1985;83:227-9. 